\title{
First Investigation of LTCC package for high temperature SAW sensors
}

\author{
J.Bardong ${ }^{1}$, A.Binder', S. Toskov', G. Miskovic ${ }^{2}$, G.Radosavljevic ${ }^{2}$ \\ ${ }^{1}$ Carinthian Tech Research, Europastraße 4/1, Austria, \\ jochen.bardong@ctr.at \\ ${ }^{2}$ Institute of Sensor and Actuator Systems, Gusshausstrasse 27-29, Vienna, Austria
}

\begin{abstract}
:
SAW temperature sensor devices have been developed for operating temperatures up to and above $1000^{\circ} \mathrm{C}$. A challenging task to make these devices available on the market is to develop an appropriate housing concept. A concept based on low temperature cofired ceramics (LTCC) has been investigated and tested under elevated temperatures up to $600^{\circ} \mathrm{C}$. The devices showed promising results up to $500^{\circ} \mathrm{C}$.
\end{abstract}

Key words: LTCC, SAW, high temperature, packaging, Langasite

\section{Introduction}

As SAW devices are widely spread as frequency filters and resonators for frequencies above $100 \mathrm{MHz}$, sensing applications are distributed among niche applications where silicon based sensors cannot be applied. For wireless temperature sensing, SAW sensors have been shown to be capable to withstand temperatures up to and above $1000^{\circ} \mathrm{C}$, but with bare crystals without housing. For easy handling and to protect the crystal, housing is needed. As packaging materials, two main families can be identified: metal can housings with glass or glass-ceramic wire feedthrough for signal routing and ceramic housings with filled vias and contacting pads. In this paper will be examined a first approach to verify if the whole assembly concept is feasible. As LTCC allows for integration of embedded antenna structures on the outside of the housing, this material has additional advantages over metal can housings: those always need to be contacted to an antenna structure for RF interrogation and tend to become leaky or break at the feedthrough. As test device, a reflective SAW delay line on Langasite (LGS) with Aluminum (Al) - Platinum $(\mathrm{Pt})$ based metallization is chosen due to its robustness [1].

\section{LTCC Housing Fabrication Process}

LTCC technology offers simplicity and rapid structuring of complex channels and cavities within a single ceramic layer due to its possibility for selection of various tapes with different thicknesses and physical characteristics. This technology is suitable for applications in harsh and corrosive environments due to excellent hermeticity, thermal and chemical resistance of ceramic material.

The designed LTCC housing contains 10 stacked ceramic layers (Fig. 1). The first two base layers carry vias, contact pads and a die bonding area for chip mounting. The layers 3 and 4 also carry vias and pads for electrical interconnection. These layers form the pocket for the LGS SAW device. The combined height of layers 3 and 4 is equal to the height of the LGS device allowing establishing the wire bonds conveniently in the same plane as the pads. The layers 5-8 are the frame layers. A screen printed sealing ring is set on the top of the 8th layer. The last two layers, 9 and 10, are combined together to form a lid for enclosure and contain an identical sealing ring on layer 9 .

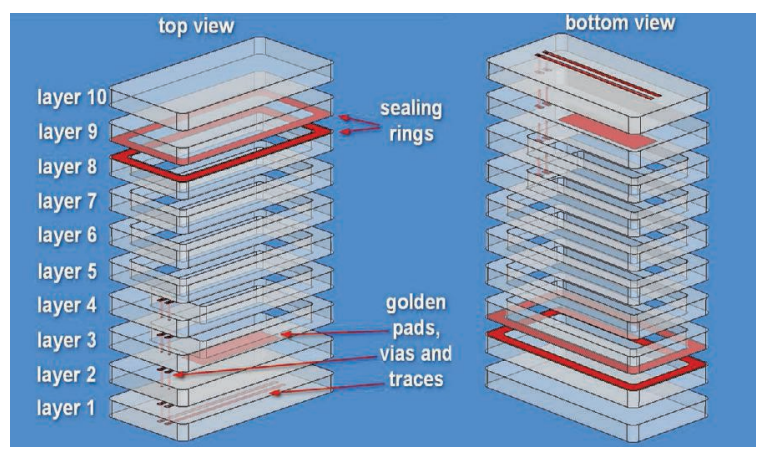

Fig. 1. 3D model of LTCC housing: top and bottom view, split up in the described layers.

The total outer dimensions of the housing are 7 $\times 13.8 \times 2.4\left[\mathrm{~mm}^{3}\right]$ for width, length and height, respectively.

The structuring of vias, channels or cavities of each ceramic layer is done in green state of the 
material by NdYAG - LASER micro-machining. Single ceramic layers carrying vias, channels, cavities or screen printed components are stacked in proper order and laminated in a thermo-compression process, followed by a sinter cycle.

For this housing, the standardized process to develop 3D structures with cavities has to be modified to achieve defect-free devices. Thus, new procedures have been developed, to take into account the size and geometry of the cavities incorporated in the LTCC tape. The main defects that occur in the standardized, thermo-compression process are the sagging of cavities and/or channels and the delamination of adjacent layers. To avoid this, the lamination of particular groups of layers should be carried out separately prior to finally thermocompressing all (sub-) groups.

The LTCC housing is fabricated using commercially available CeramTec GC LTCC tape. This tape shows pronounced reliability and stability in high temperature environments, $[2,3]$. Commercially available and compatible ESL 8881 gold conductive paste has been selected to screen print the conductive pads and traces and ESL 8835 VF gold conductive paste for the via filling. Layers 1-4 carry gold vias and screen printed golden pads on the top side of each layer. The first layer also has two golden traces on its bottom side serving as pads for electrical contacts with the exterior and a first simple antenna structure. The drying process of the gold conductive pastes was carried out at $125^{\circ} \mathrm{C}$ for $15 \mathrm{~min}$. Due to the large cavity in layers 3, 4 and 5-8, the pressure distribution during thermo-compression is nonhomo-geneous along the cross-section of the LTCC stack which may result in delamination of the bottom four layers. The delamination is a consequence of the applied pressure and temperature being too low in the area below the cavity, as this area lacks in additional mechanical support necessary for uniform pressure and heat distribution along the cross-section. Thus, the lamination process has been executed in four separated steps. In the first three steps, layers 1-2, 3-4 and 5-8 were laminated to ensure lamination integrity of each of these parts, respectively. In each step, single ceramic layers were centered and stacked together in a steel compression mold and thermally-compressed in a uniaxial press for 3.5 minutes, $75{ }^{\circ} \mathrm{C}$ and a pressure of 64 bar. The final step was dedicated to the lamination of all the previously laminated subgroups.

Then, the sintering process was carried out in three separated phases devoted to: (1) LTCC sintering in a Linn box furnace (Fig.2), (2) burn off and sintering of screen printed glass sealing rings and (3) finally sealing of the entire LTCC housing.

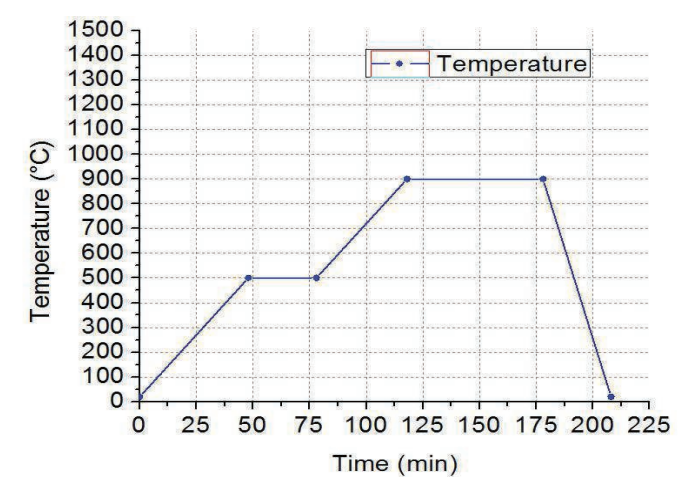

Fig. 2. Sintering phase 1: Two-step sintering profile of LTCC CeramTeC GC tape.

The binder decomposition was carried out from $20{ }^{\circ} \mathrm{C}-500{ }^{\circ} \mathrm{C}$ at $10 \stackrel{\circ}{\circ} / \mathrm{min}$, holding the end temperature for 30 minutes. Then, ceramic sintering was conducted from $500 \stackrel{\circ}{\circ}-900{ }^{\circ} \mathrm{C}$ at $10^{\circ} \mathrm{O} / \mathrm{min}$, holding $900^{\circ} \mathrm{C}$ for 1 hour. Fabricated structures after the first sintering phase are presented in Fig. 3 and Fig 4.

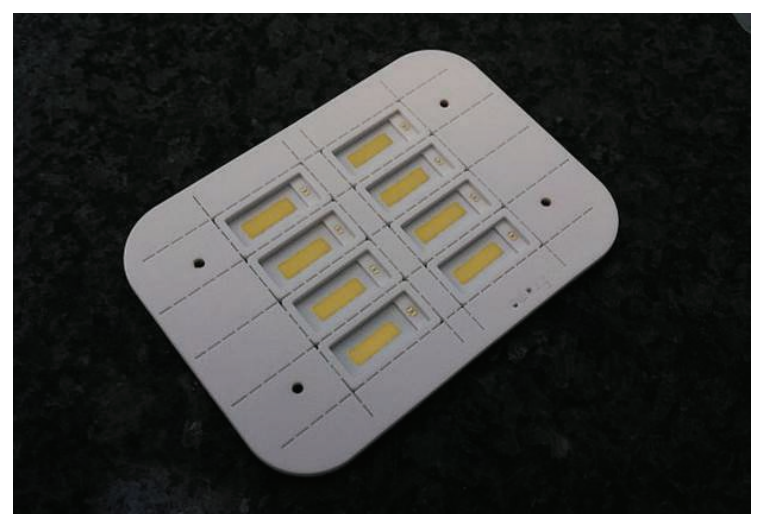

Fig. 3. Fabricated housings after two-step sintering profile of LTCC CeramTec GC tape: top view.

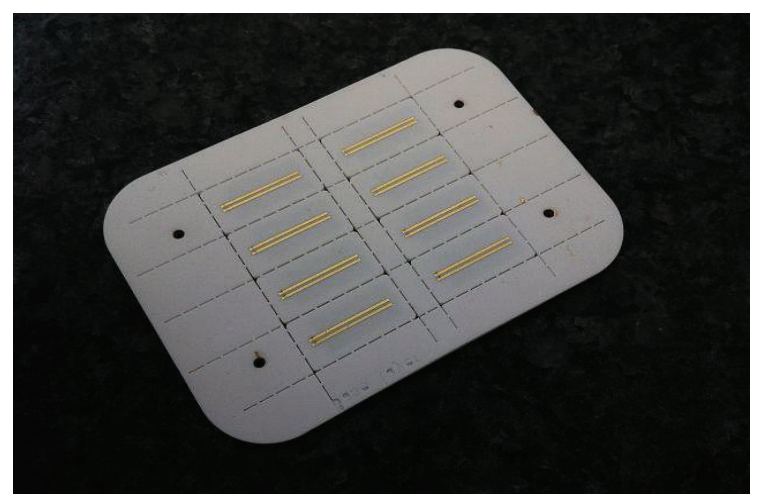

Fig. 4. Fabricated housings after two-step sintering profile of LTCC CeramTec GC tape: bottom view.

Right after the first sintering phase, the glass seals were screen printed at the top of the $8^{\text {th }}$ layer stack and the bottom side of the lid (layer 9). The drying of the ESL 4031-B glass sealing paste was done at $125^{\circ} \mathrm{C}$ for $15 \mathrm{~min}$, followed 
by the next sintering phase which was applied to burn off residual binders inside the glass paste and to sinter it to the structure, using the temperature profile shown in Fig. 5. In Fig. 6, the housing parts after these steps are presented.

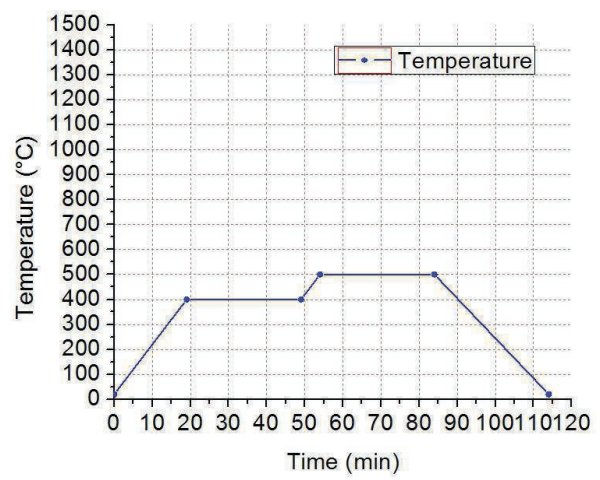

Fig. 5 Sintering phase 2: Two-step ESL 4031-B glass sealing paste burn off and sintering.

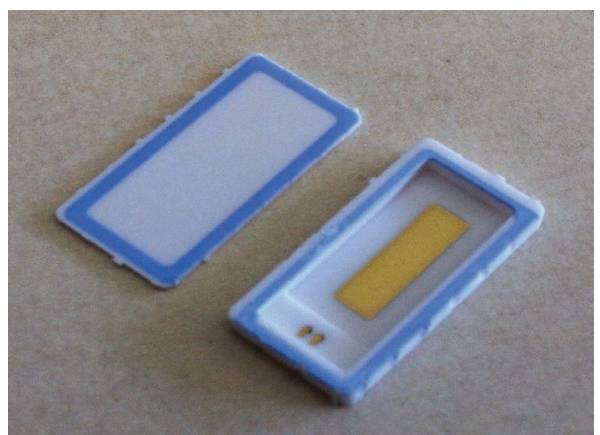

Fig. 6 Fabricated LTCC housing after ESL 4031-B glass sealing paste burn off and sintering.

\section{Assembly of test devices}

For the test, Langasite reflective delay lines with a Pt-Al stack of $105 \mathrm{~nm}$ thickness were chosen $[4,5]$. These devices showed stable readings to temperatures up to $900^{\circ} \mathrm{C}$ (Fig.7) [1].

Therefore, the dies were placed on a dispensed amount of nano paste and slowly heated to $150^{\circ} \mathrm{C}$ to drive out the organic binder. After 20 minutes, the temperature was raised to $240^{\circ} \mathrm{C}$ in 1 Minute to start the sinter process during which the silver particles form a foam-like layer and grow dendrites into the adjacent gold layers, which therefore have to have a minimum thickness of $500 \mathrm{~nm}$. After 20 minutes at this temperature level, the devices were annealed for additional 20 hours at $300^{\circ} \mathrm{C}$ to drive out residual organic compounds.

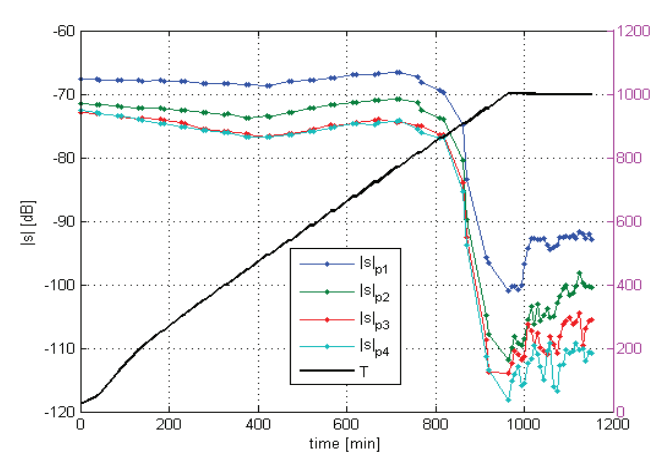

Fig. 7. Device amplitudes during annealing up to $1000^{\circ} \mathrm{C}$ in Argon. The black line indicates the linear temperature rise and corresponds with the magenta abscissa at the right. The device readings are stable up to $900^{\circ} \mathrm{C}$.

Then, the dies were wire bonded with Pt wires to the two fed-through gold pads. In Fig. 8, this setup is shown after heat treatment and reopening of the housing.

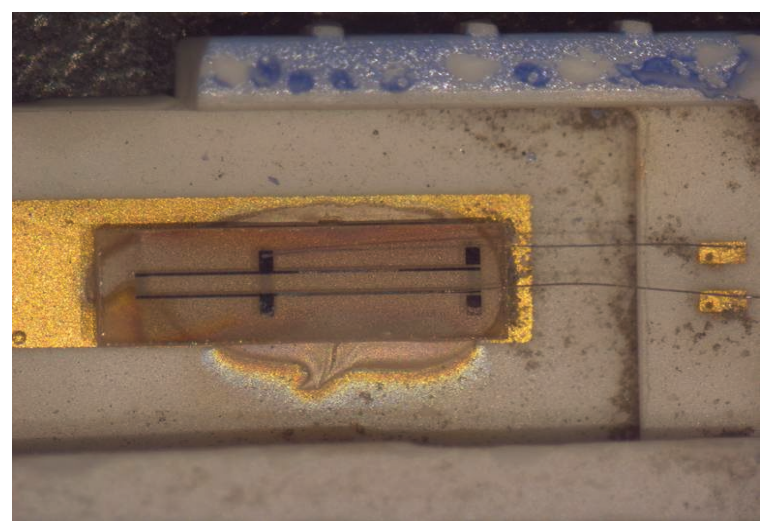

Fig. 8 Open LTCC housing after heat treatment. Langasite crystal, contacting wire bonds and silver nano paste can be identified. Residual dust from opening the device is visible between crystal and bonding pads of the LTCC.

After placing a Langasite device inside the housing and the establishing of electrical contacts, the lid was closed using a slow heating rate from $20^{\circ} \mathrm{C}$ to $550^{\circ} \mathrm{C}$ and held there for 25 minutes. Cooling down was done slowly, too to avoid thermally induced stress (Fig. 9).

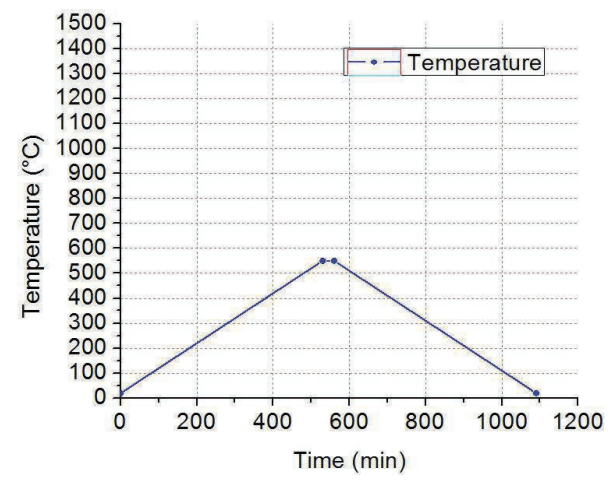

Fig. 9 ESL 4031-B sealing phase with Langasite SAW sensor inside the housing. 
The closed devices were contacted with several platinum wires to a device carrier (Fig.10) and mounted into the sample holder described in [6] and processed under the temperature setting given above. Atmosphere was $1 \mathrm{mbar}$ of Nitrogen in a tube furnace. RF interrogation was done during the measurements to the reflective SAW delaylines and analyzed.

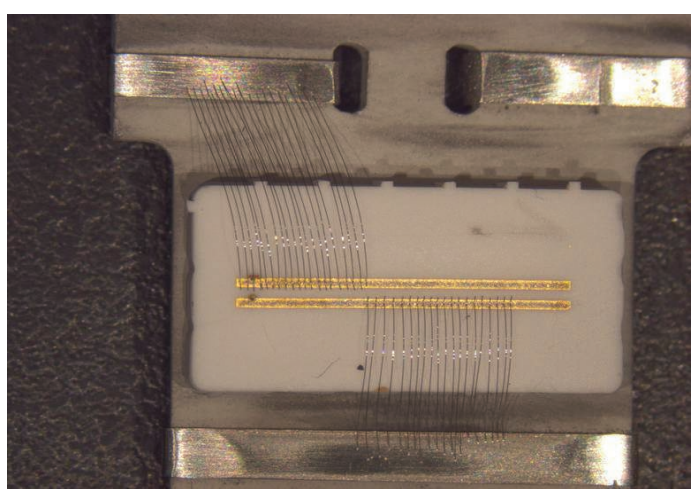

Fig. 10 Closed LTCC device, mounted on a carrier. 20 bonding wires of $25 \mu \mathrm{m}$ in diameter held the device in position and fed the signal in an out of the housing.

\section{Measurements and signal processing}

For heat treatment, the furnace was programmed to hold temperature levels from $250^{\circ} \mathrm{C}$ to $600^{\circ} \mathrm{C}$ in steps of 50 Kelvin. To get a first impression about the long-term stability, each temperature level was kept 20 hours with $\mathrm{RF}$ interrogation every 15 minutes.

Interrogation was done with reflective measurements of RF scattering parameters $\left(S_{11}\right)$ from $370-470 \mathrm{MHz}$ in $100 \mathrm{kHz}$ steps using a vector network analyzer. This allows to measure amplitude changes and delays on the transmission line, described as changes of phase angle between exciting (reference) signal and measured (reflected) signal. In Fig. 11, a plot of an exemplary device impulse response is shown.

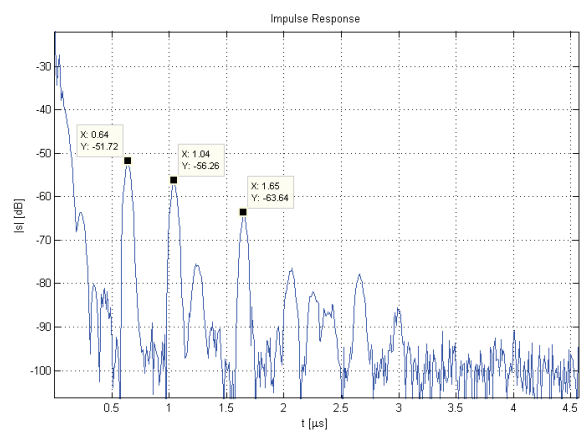

Fig. 11 Impulse response of an exemplary device. Each impulse maximum corresponds to a delay time that can be used to track temperature changes.
These complex valued signal vectors are processed semi-automatically using a computer algebra system like Octave, Scilab or commercial equivalents to derive the devices' aging behavior. In that way, the devices' signal amplitude and corresponding phase values are extracted and plotted against time (Fig.12) or temperature (Fig.13).

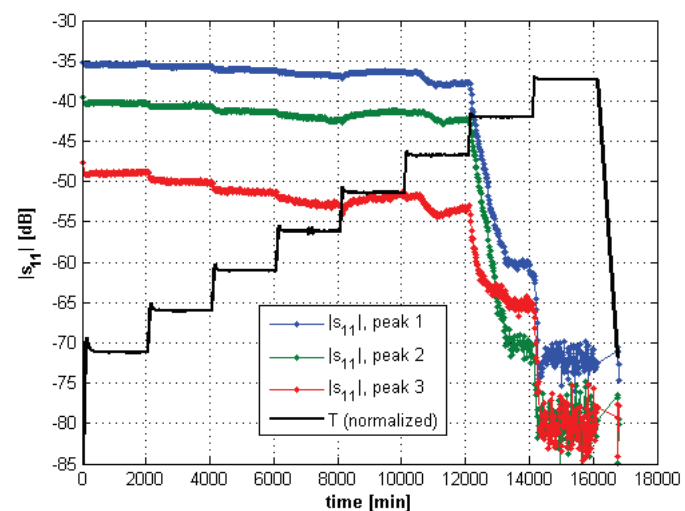

Fig. 12 Amplitude values of the three impulses during the heat treatment. At $550^{\circ} \mathrm{C}$, it drops considerably and does not recover, indicating device failure. Normalized temperature levels are shown with the black line. The first level at the left indicates $250^{\circ} \mathrm{C}$ and rises in $50 \mathrm{Kelvin}$ steps to $600^{\circ} \mathrm{C}$ on the right.

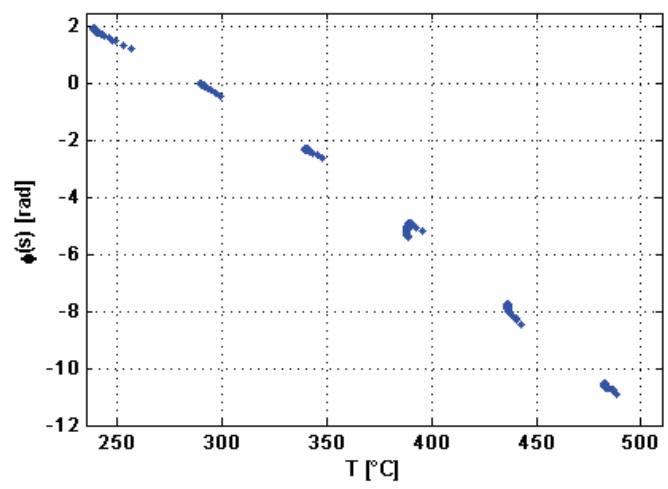

Fig. 13 Phase response plotted over temperature. It shows parabolic behavior to linear changes of temperature as can be expected from an anisotropic, piezoelectric crystal.

Whereas the amplitude holds the information of what happens to the metal layer during temperature treatment (Fig.12), the phase values show shifts corresponding to temperature changes and indicate, with growing noise, device failure (Fig.14). 


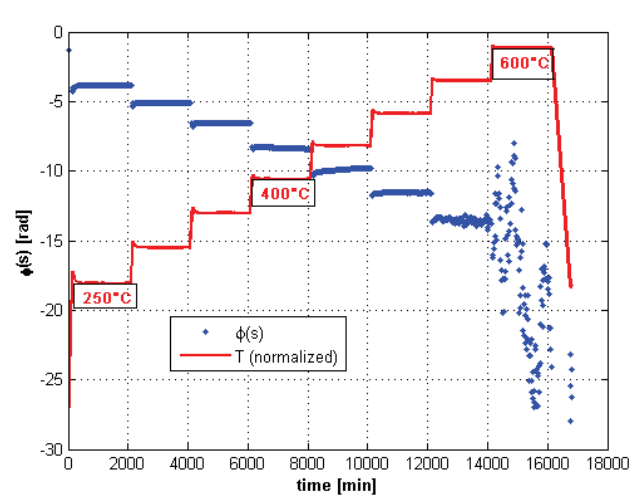

Fig. 14 Phase response of a devices' first impulse during the temperature treatment (blue). The signal is stable until $550{ }^{\circ} \mathrm{C}$, where noise is rising and device failure occurs at $600^{\circ} \mathrm{C}$. Normalized temperature is shown to indicate the good conformity of determined phase levels and temperature changes.

\section{Results}

During annealing, the devices showed good signals up to $500^{\circ} \mathrm{C}$ (Fig. $6 \& 8$ ). Above this temperature, degradation occurred. This was not expected as non-housed devices with similar design and equal Langasite and metallization material showed good stability temperatures above $700^{\circ} \mathrm{C}$ (Fig.7) [1]

Optical analysis of the structures showed considerable recrystallization, dewetting and agglomeration of the metal layers (Fig.15).

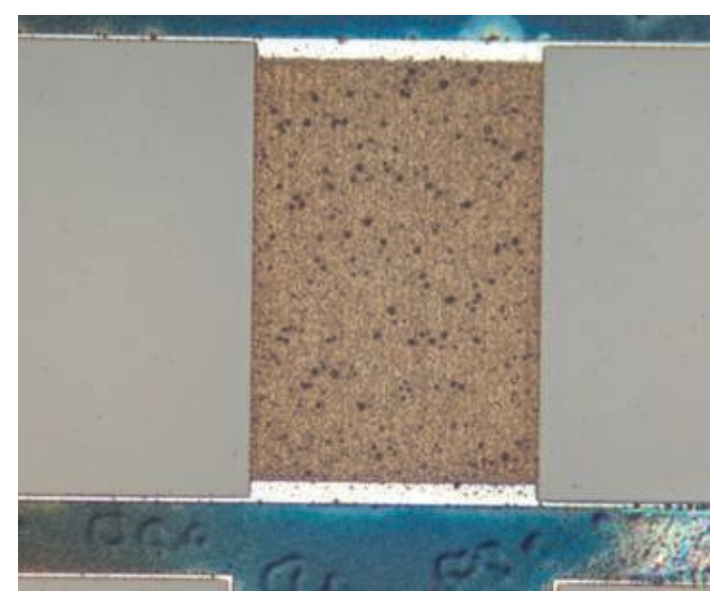

Fig.15 Detail from figure 3, center structure. Several dots on the finger structures indicate metal droplets leading to electrical shortcuts on the structure.

Mass spectroscopy examination in the temperature range from room temperature up to $600^{\circ} \mathrm{C}$ showed several mass counts matching with carbon oxides and carbon alone at the beginning of the treatment (Fig. 16 \& Tab.1). As this chemical compound can lead to a catalytic degradation of aluminum and its oxide, especially if platinum, by itself a very good catalyst, is present.
Tab. 1: Mass counts of effusion measurement

\begin{tabular}{|c|c|c|}
\hline $\begin{array}{c}\text { Atomic } \\
\text { mass }\end{array}$ & Sum formula & Name \\
\hline 2 & $\mathrm{H}_{2}$ & Hydrogen molecule \\
\hline 12 & $\mathrm{C}$ & Atomic Carbon \\
\hline 18 & $\mathrm{H}_{2} \mathrm{O}$ & Water \\
\hline 28 & $\mathrm{CO}, \mathrm{N}_{2}$ & $\begin{array}{c}\text { Carbon monoxide, } \\
\text { Nitrogen molecule }\end{array}$ \\
\hline 30 & $\mathrm{NO}$ & Nitrogen monoxide \\
\hline 32 & $\mathrm{O}_{2}$ & Oxygen molecule \\
\hline 44 & $\mathrm{CO}_{2}$ & Carbon dioxide \\
\hline
\end{tabular}

\section{Conclusions}

Due to the assembly situation (very small atmospheric volume without environmental exchange during heat treatment), it is difficult to identify the mechanism that led to the devices' degradation and failure. This leaves room for improvements.

Considering the mass spectroscopy readings showing carbon in several configurations, all assembly parts have been analyzed with respect to being a possible source of this contaminant. Langasite crystal, electrode metallization and Platinum bonding wire do not contain Carbon at any stage of production. The slurry out of which the LTCC tapes are made, the gold paste and the silver nano paste contain different kinds of solvents or binder liquids which are all organic. As the gold paste and the LTCC green tapes are annealed under Oxygen atmosphere at temperatures above $600^{\circ} \mathrm{C}$ and the silver nano paste was treated only at $300^{\circ} \mathrm{C}$ before device closing, most indicators point to the direction that the heat treatment of the assembly before enclosure has to be performed at temperatures above $600^{\circ} \mathrm{C}$.

Nevertheless, it could be shown that LTCC can be used to package RF sensor devices, showing good signals above $300^{\circ} \mathrm{C}$ - the presented system was stable up to $500^{\circ} \mathrm{C}$.

\section{Outlook}

Next steps will be thorough annealing of all system parts at temperatures above $600^{\circ} \mathrm{C}$ to reduce the possibility of residual contaminants inside the housing. From that point of view, the system is a promising candidate for high temperature RF packaging tasks as even with contaminants inside, the system performed satisfactory until $500^{\circ} \mathrm{C}$. 


\section{Acknowledgements}

The authors would like to thank M. Gillinger of TU Vienna for providing the effusion measurements.

This work is part of the ENIAC JU project EPPL - Enhanced Power Pilot Line, which is financially supported by Austria, Germany, The Netherlands, France, Italy, Portugal and the ENIAC Joint Undertaking. The Austrian part of the project is co-funded within the programme "Forschung, Innovation und Technologie für Informationstechnologie" by the Austrian Ministry for Transport, Innovation and Technology (bmvit). Also the part of this work is done within the scope of the FP7 SENSEIVER project (Low-cost and energy-efficient LTCC sensor/IR-UWB transceiver solutions for sustainable healthy environment project references 289481).

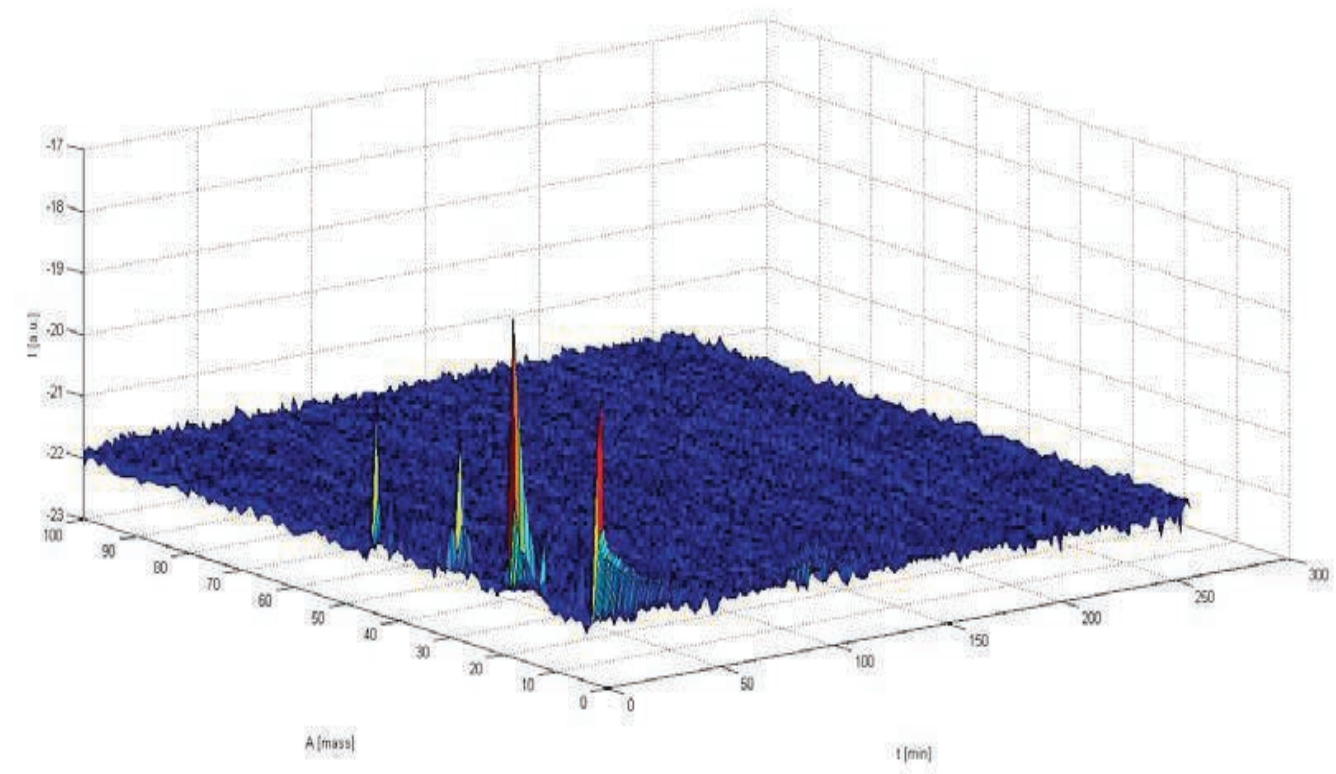

Fig.16 Effusion test graph of one device from room temperature up to $600^{\circ} \mathrm{C}$. At the very beginning of the examination, several mass counts occur, but during annealing, no additional counts are registered indicating a volatile behavior of the contaminants.

\section{References}

[1] J. Bardong, Untersuchungen platinbasierter Metallschichtsysteme auf Langasit und Lithiumniobat, Dissertation, FAM - ALU Freiburg, IMTEK, Dept. Of electrical Instrumentation, pp 105 - 116, 2013, ISBN: 9783-86247-377-9.

[2] S. Toskov, A. Maric, N. Blaz, G. Miskovic, G. Radosavljevic, "Properties of LTCC Dielectric Tape in High Temperature and Water Environment", International Journal of Materials, Mechanics and Manufacturing, Vol. 1, No. 4, pp. 332-336, ISSN: 1793-8198, DOI: 10.7763/IJMMM.2013.V1.72.

[3] M. Franz, I. Atassi, A. Maric, B. Balluch, M. Weilguni, W. Smetana, C. Kluge, G. Radosavljevic, "Material Characteristics of the LTCC Base Material CeramTape GC", Conference Proceedings of the 2012 35th International Spring Seminar on Electronics Technology", IEEE Xplore, 2012, pp. 276 - 281 ISBN: 978-1-4673-2240-9.

[4] Cunha, M. P. ; Moonlight, T. ; Lad, R. J. ; Bernard, G. ; Frankel, D. J.: Enabling Very High
Temperature Acoustic Wave Devices for Sensor \& Frequency Control Applications. In: Proceedings on IEEE 2007 International Ultrasonics Symposium, IEEE, 2007, S. 2107 2110, DOI: 10.1109/ULTSYM.2007.530.

[5] J. Bardong, G. Bruckner, R. Fachberger, Platinum based metal layer systems for high temperature SAW sensor devices on langasite, in Proc. Sensoren und Messsysteme 2010.

[6] J. Bardong, G. Bruckner, G. Franz, A. Erlacher and $R$. Fachberger, Characterisation setup of SAW Devices at high temperatures and ultra high frequencies, in Proc. (IEEE) Frequency Control Symposium, Besancon, France, May 2009, pp 28 $-32$. 